\title{
Chapter 39: Toxin mixture in cyanobacterial blooms - a critical comparison of reality with current procedures employed in human health risk assessment
}

\author{
Dietrich DR, Fischer A, Michel C, Hoeger SJ
}

\begin{abstract}
Cyanobacteria are the oldest life forms on earth known to produce a broad spectrum of secondary metabolites. The functions/advantages of most of these secondary metabolites (peptides and alkaloids) are unknown, however, some of them have adverse effects in humans and wildlife, especially when ingested, inhaled or upon dermal exposure. Surprisingly, some of these cyanobacteria are ingested voluntarily. Indeed, for centuries mankind has used cyanobacteria as a protein source, primarily Spirulina species. However, recently also Aphanizomenon flos-aquae are used for the production of so called blue green algae supplements (BGAS), supposedly efficacious for treatment of various diseases and afflictions. Unfortunately, traces of neurotoxins and protein phosphatases (inhibiting compounds) have been detected in BGAS, making these health supplements a good example for human exposure to a mixture of cyanobacterial toxins in a complex matrix. The discussion of this and other possible exposure scenarios, e.g. drinking water, contact during recreational activity, or consumption of contaminated food, can provide insight into the question of whether or not our current risk assessment schemes for cyanobacterial blooms and the toxins contained therein suffice for protection of human health.
\end{abstract}

\section{Cyanobacterial metabolites: Health hazards for humans?}

Cyanobacteria exist worldwide ubiquitously, including in extreme environments (Hitzfeld et al. 2000a; Wynn-Williams 2000). Some of these 
cyanobacterial species produce complex compounds at great energy expense. The ecological or physiological function or advantage of these compounds for these cyanobacteria species is yet unknown. Toxic cyanobacterial blooms, whether on the surface, benthic growths or as subsurface layers of fresh, brackish or marine water bodies have been responsible for numerous acute and subacute intoxication incidents of humans and animals. Most of these toxic metabolites are very small alkaloids or peptides, with a molecular weight of $<2 \mathrm{kD}$, a very complex structure and, in case of the peptides, composed of uncommon amino acids. Amongst the alkaloids synthesized by cyanobacteria are e.g. saxitoxins or anatoxins, known to be toxic for humans and other organisms at very low concentrations (Hitzfeld et al. 2000b). The cyanobacterial peptides are not metabolized in the mammalian digestive tract due to the presence of $\mathrm{D}$-amino acids and a cyclic structure. Consequently, either local toxicity, e.g. diarrhea, or systemic toxicity, e.g. hepatotoxicity, neurotoxicity, renal toxicity i.e. morbidity or even mortality are the direct consequences of acute exposure. However, the uptake of these toxins and their organ distribution appears to be mediated by specific transporters, of which most, if not all, remain unidentified in humans and other mammalian species (Fischer et al. 2005). An exception to the latter is the uncommon, non-protein amino acid $\beta-\mathrm{N}-$ methylamino-L-alanine (BMAA), a neurotoxin, which is probably produced by most likely all known groups of cyanobacteria (Cox et al. 2005).

In order to provide a reasonable hazard and risk assessment for these toxins in conjunction with acute or chronic exposures, it is prerequisite to characterize their uptake and distribution (kinetics) and consequently the toxic dose that induces in-situ effects (dynamics). Moreover, it is essential to understand the kinetics and dynamics and thus the hazard and risk of single toxins before the hazard and risk of toxin mixtures can be evaluated and meaningful risk management strategies can be developed.

In the environmental setting, not every cyanobacterial family or even every strain within a family synthesizes highly toxic alkaloids and peptides, meaning that the simple occurrence of cyanobacteria in a water body does not mandate the presence of cyanobacterial toxins. In order to ensure that a given water body is free of or has only a limited contamination with toxins, specific toxin analyses should be carried out. However, to do this on a routine basis can be financially problematic, thus calling for a prioritization of water bodies and definition of sampling routines that would ensure the highest degree of safety at reasonable cost. First and foremost, all water bodies in use as drinking water resources must be monitored routinely, the frequency of analyses should be determined based on the cyanobacterial history of the water body and the observation of the water body by qualified personal. However, even oligotrophic lakes can contain 
blooms of toxic cyanobacteria that are not readily and routinely observable. Especially Planktothrix rubescens, the species having the highest microcystin concentration/cell of all known cyanobacteria, occurs specifically in the metalimnion of oligotrophic and deep lakes, sometimes even during winter. Second, water bodies used for aquaculture (fish, shrimp and shellfish) must be monitored and the products harvested must be controlled for contamination with known cyanobacterial toxins, since for some of them (e.g. BMAA) bioaccumulation and trophic transfer has been demonstrated. Especially lakes in use for harvesting and the production of cyanobacterial food supplements must be monitored and a product and consumption derived limit of acceptable contamination defined. Finally, water bodies used for recreational purposes must be monitored and the bathing areas must be closed, if the concentration of cyanobacterial toxins is considered to endanger human health, especially children and toddlers.

For risk assessment and risk management purposes one would be inclined to try to differentiate and classify species that occur specifically only in one given environment, and thus, to try to deduce the possible type(s) of toxins that could potentially evolve from a bloom of this species in the given environment. This approach, however, has so far proven to be unsatisfactory due to the following observations:

- While some cyanobacterial species appear to prefer specific environments (e.g. Nodularia spumigena, Planktothrix rubescens), others are found nearly in all environments (Lyngbia sp.)

- Cyanobacterial blooms may be predominated by one given cyanobacterial species, however this does not exclude the quantitatively important presence of another toxin producing species

- Blooms of different cyanobacterial species (e.g. Anabaena circinalis and Microcystis aeruginosa) have been observed to occur in the very same water body at different time-points but also sometimes overlapping when occurring in rapid succession to one another

- Many cyanobacterial species have been observed to be capable of producing several different toxin types as well as different toxin congeners (e.g. microcystin congeners)

- Bloom size, expressed as cells density (cells/ml), are not a reliable indicator for toxin production especially as large blooms have been reported that did not produce extensive toxin amounts, while conversely blooms containing low to moderate cell densities have been demonstrated to produce copious amounts of toxin. 
The following two examples may serve as an illustration of the above points:

1. In 1996 an intensive phytoplankton bloom was observed in the Montargil reservoir, Portugal. From May to June Aphanizomenon flosaquae had been the predominant species and bloom extracts exhibited clear neurotoxic symptoms in a mouse bioassay. Pereira et al. (2000) analytically identified five saxitoxin variants following the isolation of an A. flos-aquae strain predominating the bloom. From July to August Microcystis aeruginosa predominated the bloom with extracts showing high hepatotoxicity in the mouse bioassay. The observed hepatotoxicity was attributed to the presence of high concentrations of microcystins. Although the two cyanobacteria species occurred in the bloom with alternating predominance, $A$. flos-aquae was still present in considerable densities during $M$. aeruginosa predominance. However, despite the presence of large numbers of $A$. flos-aquae no neurotoxicological activity (AOAC mouse bioassay) was observable suggesting that the A. flos-aquae strains co-occurring within the $M$. aeruginosa bloom did not produce saxitoxin at all or, at least not in relevant quantities. It seems that in the Montargil reservoir several saxitoxin producing and non-producing strains coexist within the same bloom but with varying densities. Alternatively, the A. flosaquae in the Montargil reservoir was only one strain of A. flos-aquae with rapidly changing capabilities of producing saxitoxins.

2. In a drinking water reservoir in Australia where M. aeruginosa and $A$. circinalis were the predominant cyanobacteria, Hoeger et al. (2004) found that the highest concentrations of microcystins produced by $M$. aeruginosa did not coincide with the highest cell counts. This could, as suggested above, indicate the simultaneous presence of non-toxinproducing and toxin-producing strains of $M$. aeruginosa. In contrast, saxitoxin(s) concentrations found appeared to be highly correlated with the cell densities of $A$. circinalis, suggesting that only one continuously toxin-producing strain of $A$. circinalis was present in this specific water body.

The two examples above strongly illustrate the importance of detailed understanding of the limnological and toxicological characteristics of a specific water body, i.e. the spatial and temporal occurrence of toxin(s) and cyanobacterial species present in a given bloom. Consequently, generalized statements regarding the species and toxins occurring in a specific water body, or water bodies in general, is difficult if not impossible. Reliable risk characterization of possibly toxic blooms demands assessment of 
the cyanobacterial species and toxins by specialists or trained personnel, and a thorough understanding of the limnological history of the respective water body concerned.

Taking the above points regarding the characterization of bloom events into consideration, it becomes stringently clear that each and every bloom event in a given water body represents a unique risk scenario for humans and animals. In order to reduce complexity and facilitate understanding of the main issues at hand, the following discussion primarily focuses on human health risks. The discussion of the possible exposure scenarios in conjunction with the toxin specific health risk extrapolations will provide insight into the question as to whether or not our current risk assessment schemes for cyanobacterial blooms suffice for protection of human health as well as pin-point areas where more profound understanding of the underlying toxicity mechanisms is needed.

\section{General risk scenarios (cyanobacterial blooms)}

Massive toxic cyanobacterial blooms of concern for humans predominantly occur in fresh water bodies used for the preparation of drinking water and recreational activities. Consequently, human cyanobacterial toxin exposure can occur either via contaminated drinking water or during recreational activities in cyanobacteria blooming water. The exposure scenarios that follow are therefore artificially divided into the two predominant human exposure routes, namely oral and inhalation exposure. Although dermal exposure and subsequent effects have been described in the literature (Pilotto et al. 1997; Soong et al. 1992; Stewart et al. 2001; Torokne et al. 2001), primarily as anecdotal reporting of incidences without a experimental follow-up and/or proof of principle analysis, the cyanobacteria and toxin(s) causally responsible for the reported dermal effects have not been established with the exception of Lyngbya majuscule. The contact with this species causes dermatitis, and accidental oral consumption led to an burning sensation in the mouth (Osborne et al. 2001).

\section{Oral exposure}

The oral exposure scenario assumes that the person is exposed voluntarily or accidentally. In both situations, it is the goal of the risk assessment to elucidate the highest toxin concentration in the water that has no health 
consequences for the exposed person ingesting a given volume of water in an acute (one time ingestion) or chronic (continuous ingestion) situation.

\section{Drinking water}

For drinking water, one of the primary concerns is whether water treatment can eliminate or reduce the concentration of the cyanobacterial toxins present during a bloom event. Although this generally appears to be the case for most technically moderately modern water treatment systems (Hitzfeld et al. 2000b; Hoeger et al. 2005) and bloom situations, exceptions to the rule do occur (Hoeger 2005).

In the years $1985-1988$ recurring cases of severe gastro-enteritis were observed in Bahia State, Brazil, apparently closely associated with the consumption of treated and untreated water from the Itaparica Dam reservoir (Teixera et al. 1993). Although cases of gastro-enteritis and associated diarrhea were observed throughout the years at low incidence, increased numbers of cases with concurrent hospitalization and subsequent mortalities occurred regularly between January to May of each year. In 1988 the most severe outbreak of gastro-enteritis and associated diarrhea with fatal outcome occurred between February and May. Of approximately 2392 reported cases of gastro-enteritis, 368 were immediately hospitalized. The average monthly mortality among the hospitalized patients was $24 \%$ with a peak of $45.1 \%$ in May. No abnormalities in the frequency of diarrhea incidences arose in adjacent regions with a different drinking water source. Clinical/microbial investigations of the water from the Itaparica dam reservoir treated water did not identify the presence of fecal coliforms, salmonella, shigella, adenovirus or rotavirus. Boiling and filtration of the treated water had no impact on the occurrence of severe gastroenteritis. Accordingly, it appeared that the agent in the treated water was heat and filtration resistant, possibly pointing to cyanobacterial toxins e.g. microcystins. Limnological analyses of the dam water in April 1988 revealed the presence of Anabaena and Microcystis species at densities exceeding the WHO maximum acceptable levels for untreated drinking water by a factor $4-33$. Seventy percent of the hospitalized gastro-enteritis cases were children under the age of 5 in the period between March and May, 1988. The high incidence of illness among children suggests that risk calculations based on data from human adults or animal studies may not be sufficiently protective for children.

In 1999 and 2000 a survey of cyanobacterial toxins in surface waters and drinking water supplies was carried out across Florida, USA, revealing the following concentrations of cyanotoxins in raw and treated/drinking water (Burns 2004): 
- concentrations of microcystins ranged from below the detection limit to $12.5 \mu \mathrm{g} / \mathrm{l}$ in raw and treated/drinking water samples

- concentrations of anatoxin-a ranged from below the detection limit to $8.46 \mu \mathrm{g} / \mathrm{l}$ in three treated drinking water samples

- concentrations of cylindrospermopsin ranged from 8.07 to $97.12 \mu \mathrm{g} / \mathrm{l}$ in nine treated drinking water samples. In some cases, trichomes of Cylindrospermopsis raciborskii in the raw water survived the treatment process and were present in the tap water.

An acute maximum dose that is not toxic to infants, small children or adults can be extrapolated from the lowest acute toxic doses of cyanotoxins observed in mouse studies using body weight assumptions (Dietrich and Hoeger 2005; Fromme et al. 2000). For example, a single intake of $12.5,50$ or $150 \mu \mathrm{g}$ microcystin-LR (MC-LR) equiv. are assumed not to produce adverse effects in toddlers $(<5 \mathrm{~kg} \mathrm{bw})$, small children $(>20 \mathrm{~kg}$ bw) and adults (60 kg bw), respectively. However, such calculations are fraught with difficulties as it is unclear:

- how much of the compounds are actually biologically available in humans

- whether or not direct extrapolations from mouse studies to humans are reliable as there are vast species differences in toxin specific transporter expression in the gastro-intestinal tract (see below).

- whether or not extrapolations from single toxin toxicity experiments are feasible, in view of the fact that multiple toxins may occur in a bloom simultaneously and because there is lack of knowledge regarding combinatorial toxicity.

For the calculation of safe levels for chronic exposure, estimates of drinking water intake and average body weights must be used. The average daily consumption of water varies between 1500 and $2000 \mathrm{ml}$ of treated (drinking) water per day for adults with an average weight between $50-80 \mathrm{~kg}$ bw. For infants and small children average daily water consumption is assumed on average to be $750 \mathrm{ml}$ and $1000 \mathrm{ml}$ per day, respectively (Dietrich and Hoeger 2005). In all calculations, the assumptions are made that treated water is consumed, consumption will occur nearly for a life-time, and that only one of the variety of cyanobacterial toxins will occur at any one given time. However, toxic cyanobacteria are unlikely to be continuously present, different cyanotoxins toxins can be present at the same time in varying concentrations, and water treatment procedures do not always guarantee cyanotoxin removal. 


\section{Recreational Activities}

All activities at, in, and on the surface of the water body that bring humans into direct contact with water are considered to be recreational activities. These include bathing, swimming incl. contests e.g. triathlons, water skiing, boating, etc. While pursuing these activities it is assumed that some toxin-contaminated water will be accidentally and involuntarily ingested. The amount of water ingested is - in a worst-case situation - approximated as ranging from $50-120 \mathrm{ml}$ per episode. As this is usually an intermittent rather than a continuous occurrence, with the exception of people continuously swimming and bathing in a water body chronically contaminated with toxic cyanobacteria blooms, all risk calculations are driven toward an acute exposure scenario. The following episode is an example of this type of exposure:

Turner et al. (1990) reported cyanobacterial poisoning of two 16 - year old army recruits. Both became ill after a canoe exercise on a freshwater reservoir in Staffordshire, England, experiencing a massive M. aeruginosa bloom containing high concentrations of MC-LR. Both swallowed some of the water; both recruits developed pneumonia and other symptoms including blistering around the mouth, sore throat, dry cough, pleuritic pain, vomiting and abdominal pains requiring medical attention. One of the patients presented with temporary difficulties in walking, suggesting possibly neurotoxic effects. Subsequently another sixteen soldiers received medical attendance also after canoeing. Eight exhibited some symptoms similar to the first two cases. The disease pattern was considered to stem from microcystin intoxication, even though two weeks later a critical contamination of the reservoir with Escherichia coli was confirmed. The coincident presence of $M$. aeruginosa and E. coli could suggest a simultaneous exposure of the recruits to MC-LR and lipopolysaccharides (LPS) because the patterns of symptoms, with possibly the exception of the transient neurological disorder, are characteristic for a MC and LPS exposure. The neurological symptoms could be due either to MC (Fischer et al. 2005) or other neurotoxic cyanotoxins. In addition, augmentation and exacerbation (additive or synergistic) of effects and symptoms due to simultaneous exposure to different toxins (MC and LPS) cannot be excluded (Best et al. 2002).

\section{Specific health risks from contaminated food and cyanobacterial food supplements}

Contrary to the direct exposure of humans to cyanobacterial toxins via contaminated water, the risk situation involving exposure via food and food supplements is much more complex. Worst-case exposures can be in- 
terpolated from assumed daily or weekly consumption of specific food sources e.g. fish, crayfish, shellfish, vegetables, salads, etc. for the general populace as well as for populations at high risk, e.g. indigenous tribes predominantly existing on a specific food source (Dietrich and Hoeger 2005; Ernst et al. 2005). However, the potential human toxin exposure via food that provides the basis for risk calculations is also largely determined by the degree of toxin contamination of a given food source as well as by the bioavailability of the toxin from the food type. Furthermore, although most likely an exception to the rule, bioaccumulation of cyanotoxins in the food chain, as is the case with $\beta-\mathrm{N}$-methylamino-L-alanine (BMAA), may provide for an additional element of risk (Cox et al. 2005).

Exposure considerations similar to those for drinking water also apply to the voluntary consumption of cyanobacteria (blue-green alga) food supplements on the basis of cyanobacteria, also know as blue-green alga supplements (BGAS). The main difference is that the daily consumption of pills, powders and drinks is extremely difficult to estimate. Furthermore, these products are often handled as if they were pharmaceuticals. Therefore, the consumption per person does not correspond to body weight as is the case for real food sources, e.g. fish, crayfish etc. A detailed discussion of this issue can be found in Dietrich \& Hoeger (2005), a publication that also estimates the effects of varying levels of microcystin contamination of food and food supplements and the corresponding limit amount that can be safely consumed by infants, children and adults (Table 1).

BGAS are usually produced from Spirulina maxima or platensis and Aphanizomenon flos-aquae. Although Spirulina maxima is considered as being non-toxic (Salazar et al. 1996; Salazar et al. 1998), Draisci et al. (2001) identified Epoxyanatoxin-a and Dihydrohomoanatoxin-a at concentrations ranging from non detectable to $19 \mu \mathrm{g} \mathrm{g}^{-1} \mathrm{dw}$ in Spirulina-based BGAS.

In alkaline crater lakes in Kenia, Arthrospira fusiformis (syn. Spirulina fusiformis = platensis) was found to produce small amounts of both, microcystins and anatoxin-a (Ballot et al. 2004; Ballot et al. 2005). Positive ELISA - results were evidence for a possible contamination of Spirulina supplements with microcystins (Gilroy et al. 2000). In addition, Spirulina based BGAS is suspected to be responsible for the liver injury of a 52-year old Japanese (Iwasa et al. 2002). Further corroboration of these data is necessary before proper evaluation of the potential hazard to human health in the context of a risk assessment can be carried out.

Contrary to Spirulina, where direct production of toxin is yet uncorroborated, A. flos-aquae is known to be capable of producing the neurotoxic alkaloids anatoxin-a (Rapala et al. 1993) and saxitoxins (Adelman et al. 
1982; Ferreira et al. 2001; Mahmood and Carmichael 1986; Pereira et al. 2000), as well as the neurotoxic, nonprotein amino acid BMAA (Cox et al. 2005). Maatouk et al. (2002) assumed that a mono-specific Aph. flosaquae bloom was responsible for the microcystin content of a Aph. flosaquae sample from Saint-Caprais reservoir in France. The cytotoxic and most likely carcinogenic alkaloid cylindrospermopsin has yet not been detected in Aph. flos-aquae, however its presence in Aph. ovalisporum is confirmed (Banker et al. 1997; Shaw et al. 1999).

In contrast to Spirulina, Aph. flos-aquae is generally harvested from natural lakes. One of its biggest sources is Lake Klamath, Oregon, where Aph. flos-aquae co-exists and coincides with Microcystis sp. blooms (Carmichael et al. 2000), this coexistence can also be observed in other lakes (Ekman-Ekebom et al. 1992; Teubner et al. 1999). Consequently, consumers of Spirulina- and Aph. flos-aquae -BGAS are potentially exposed to toxins produced by all three of the cyanobacteria species.

Although neurotoxic alkaloids (anatoxins and saxitoxins) have not been identified to date in Klammath Lake, Sawyer et al. (1968) reported on an aqueous extract of an Klamath Lake Aph. flos-aquae bloom that was nearly instantaneously lethal to mice after i.p. injection. In addition, Aph. flos-aquae was reported to be responsible for massive fish kills (Barica 1978) and being generally highly toxic to members of the freshwater fauna (Gentile and Maloney 1969). Out of 88 bloom samples from Finland in which Aph. flos-aquae was one of the predominating species, 11 were determined to be neurotoxic and 25 to be hepatotoxic (Sivonen et al. 1990). Acute toxicity testing of 23 populations of Aph. flos-aquae from 12 localities of inland waters in South Norway, resulted in protracted toxic response in the test animals with $60 \%$ of the samples tested (Underdal et al. 1999).

Several investigations report high concentrations of microcystins in BGAS products (Hoeger and Dietrich 2004; Lawrence et al. 2001; Saker et al. 2005; Yu et al. 2002), often dramatically exceeding the provisional guidance value of $1 \mu \mathrm{g} / \mathrm{g} \mathrm{dw}$ set by the Oregon Health Division and the Oregon Department of Agriculture (Gilroy et al. 2000). Based on some major weaknesses in the assumptions underlying the risk assessment leading to this provisional guidance value, Dietrich and Hoeger (2005) concluded that BGAS could pose a serious health risk to consumers, especially children. One of the main weaknesses in the risk calculation process is the assumption that all congeners of a toxin, in this case microcystins have the same toxicokinetic and -dynamic properties, i.e. that all congener concentrations in a given example can be added up to give one single MC$\mathrm{LR}_{\text {equiv. }}$ concentration. Another weakness is that all of the risk calculations are focused on risk of a single compound exposure situation but not, as 
was shown above, on the potential simultaneous exposure to multiple toxins of vastly different structure, kinetics and dynamics, ignoring possible additive or even synergistic effects, as will be discussed later in the text. The toxicity of BGAS supplements is particularly worrisome because the benefits of the consumption of BGAS are still unclear and could not be confirmed scientifically (Vitale et al. 2004).

\section{Inhalation exposure through drinking/hygienic water}

Inhalation exposure to cyanobacterial toxins stems primarily from three exposure situations, namely habitation near chronically contaminated surface waters, use of contaminated water for hygienic purposes (showering and sauna), and finally during recreational activities as already indicated above. The problem is that good exposure models are lacking. Only rough assumptions can be made for the amount of toxin and toxic cyanobacterial cells available in an aerosolic form and for the average inhalation rate (liters minute ${ }^{-1}$ ) of the persons potentially exposed to the cyanobacteria and their toxins. Needless to say that the average inhalation rate of a person involved in a high-energy recreational activity e.g. swimming/triathlon competition, water skiing or those involved in a moderate activity e.g. swimming leisurely, boating, etc or those living at the coast-line of a chronically bloom contaminated surface water will be entirely different. The following examples illustrate situations in which adverse effects from inhalation exposure was very likely although proper documentation is missing:

Hoppu et al. (2002) reported cases where cyanobacterial contaminated water was used for washing and for producing hot steam in a sauna in Finland. By pouring cyanobacteria containing water on heated stones, cyanobacterial cells may be lysed, toxins released and aerosolized. As a consequence, people could experience both dermal and inhalation exposure to cyanotoxins via contaminated water and aerosols. Subsequent to sauna and bathing, 48 persons developed gastrointestinal, dermal and neurological symptoms most likely attributable to cyanobacterial toxin exposure. Unfortunately no information was available on the cyanobacteria species or the cyanotoxins present in the water used for bathing and the sauna.

A similar situation may have occurred in Florida, where copious amounts of microcystins, anatoxin-a and cylindrospermopsin as well as trichomes of Cylindrospermopsis raciborskii were reported in raw and treated water (Burns 2004). Inhalation exposure could have taken place especially in showers, as shower water usually exceeds $70^{\circ} \mathrm{C}$ during the heat- 
ing process, cyanotoxins are released from cells due to heat lysis, and

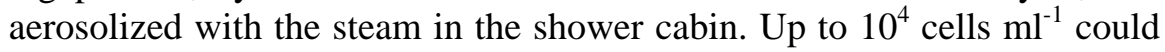
be counted in the tap water in a town in Queensland/Australia (Hoeger et al. 2004). Although no exposure related effects were reported for residents in either case, the above examples demonstrate that high cell numbers of potentially toxic cyanobacteria can pass water treatment and provide a basis for inhalation, dermal and oral toxin exposure.

Furthermore, the above examples demonstrate that exposure to multiple toxins via inhalation can most likely occur. Heating of cyanobacteria contaminated water and aerosolization of cyanobacterial components may provide a form of exposure unlikely to occur under other circumstances (bathing, etc.). Consequently it is at present unclear whether the risk assessment calculations carried out with known cyanobacterial toxins offer any safety for the inhalation exposure scenario.

\section{Human health risk assessment single vs. multiple compounds: toxicokinetic and -dynamic considerations}

Investigations of cyanobacteria intoxication events have so far focused on MCs due to their frequent occurrence, high toxic potential, and clear association, if not causal relationship, with severe poisonings of humans (Kuiper-Goodman et al. 1999) and animals (Landsberg 2002). As most of these incidences were related primarily to ingestion of contaminated water, the WHO (Chorus and Bartram, 1999) developed a provisional guidance value of $1 \mu \mathrm{g}$ MC- $\mathrm{LR}_{\text {equiv }} \mathrm{L}^{-1}$ for drinking water, based on data from a mouse study using purified MC-LR. A similar study with pigs and MC containing extracts resulted a nearly the same no/lowest observed adverse effect value (Dietrich and Hoeger 2005).

Toxicological studies using MC containing extracts inherently appear to have a greater relevance for assessment of potential toxicological hazards to human health than those using one purified congener. To date numerous studies on the toxicity of purified MCs, MC-LR in particular, and of MC containing extracts have been carried out using different test organisms and different routes of administration. Despite that microcystins have generally been characterized as hepatotoxins, there is also evidence for neurotoxicity, as suggested in the Caruaru incident, where more than 60 dialysis patients died following i.v. treatment with MC contaminated dialysis water (Azevedo et al. 2002; Fischer et al. 2005; Jochimsen et al. 1998; Pouria et al. 1998), and for nephrotoxicity, as indicated by several animal experiments (Bhattacharya et al. 1997; Fischer and Dietrich 2000; Khan et al. 
1996; Milutinovic et al. 2002; Milutinovic et al. 2003; Moreno et al. 2005; Stotts et al. 1997). Studies on organ distribution support these findings and suggest that, beside liver and kidney, the brain and the lungs (Picanco et al. 2004) can also be affected to a varying extent (Dietrich and Hoeger 2005; Meriluoto et al. 1990; Pace et al. 1990; Robinson et al. 1989; Robinson et al. 1991; Stotts et al. 1997).

Since microcystins are charged and spatially large molecules they cannot cross cell membranes via simple diffusion, thus cellular uptake is most likely mediated by energy dependent transporters. Indeed, Runnegar (1995) assumed sinusoidal, bile-salt, organic-anion transporters, including members of the superfamily of organic anion transporting polypeptides (human: OATP; rodent: oatp), are the unlikely transporting route for mediating the uptake of microcystins into hepatocytes, because rifamycin inhibited the MC uptake in hepatocytes (Runnegar et al. 1995), whereas rifampicin, a member of the same antibiotic family as rifamycin, did not inhibit the transport capacity of the investigated oatp (Jacquemin et al. 1994; Jacquemin et al. 1991). However, more detailed investigation by Fischer et al. (2005) demonstrated the uptake of $\left[{ }^{3} \mathrm{H}\right]$-dihydro-microcystin-LR in Xenopus laevis oocytes via human OATP1B1 and OATP1B3, both located at the basolateral (sinusoidal) membrane of hepatocytes, as well as OATP1A2, located in liver and brain, possibly responsible for the observed hepatotoxicity and neurotoxicity, respectively. Transport could be inhibited by co-incubation with the known OATP/oatp substrates taurocholate and bromosulfophthalein.

OATPs/oatps could be detected in nearly all tissues of humans and rodents (Hagenbuch and Meier 2003; Meier and Stieger 2002; van Montfoort et al. 2003) and therefore might be responsible for the observed microcystin mediated effects in the various organs of the respective species. Whether only OATPs/oatps mediate the transport of microcystins is presently unknown. However, this appears rather unlikely as not every organ is observed to express OATPs, at least according to current knowledge. Generally OATPs are responsible for importing substrates into cells, although bidirectional transport was also observed in some cases. Multidrug Resistance Proteins (MDRs) and Multidrug Resistance associated Proteins (MRPs), both members of the ATP Binding Cassette superfamily (ABC transporters), are other potential mediators for the export of microcystins for the following reasons:

- MCs fit into the molecular weight spectrum of MDRs and MRPs substrates (table 1) 
- The uptake of MCs was shown to be inhibited after protein phosphatase inhibition, suggesting that at least some of the responsible carriers are controlled via phosphorylation (Runnegar et al. 1995)

- Most of the MRPs are known to transport glutathione conjugates and MCs were demonstrated to be conjugated with glutathione (Pflugmacher et al. 1998)

- Glutathione conjugated microcystins were observed in the bile of microcystin exposed animals (Sahin et al. 1994)

- MRD and MRP are expressed at the apical side (hepatocyte/bile membrane) of hepatocytes as well as the basolateral side of bile cells (Hagenbuch et al. 2002; Hagenbuch and Meier 2003, 2004; van Montfoort et al. 2003).

The assumption that these ABC transporters and OATPs (Ballatori et al. 2005; Faber et al. 2003; Hagenbuch and Meier 2003; Ho and Kim 2005; Kunta and Sinko 2004; Meier and Stieger 2002; Miyazaki et al. 2004; Nies et al. 2004; Shitara et al. 2005; van Montfoort et al. 2003) are the responsible carriers for MCs would potentially explain some of the organ distribution characteristics of MC-LR after oral intoxication. However, none of these investigations was carried out using other MC congeners. Indeed, in vivo evidence from Milutinovic et al. (2002; 2003) strongly suggests that transport of microcystins via ABC transporters and OATPs is largely congener dependent, and thus, results in a congener dependent organ distribution and distribution-mediated intensities of adverse effects. Further characterization of the transport of microcystins via OATPs, as well as other potential transport systems, is of prime importance for improving better understanding of the species- and congener-specific kinetics and thus for improved risk extrapolation and human risk assessment-

Based on the current state of the science, the risk assessment of microcystins is hampered by the following inadequacies as summarized below:

- >80 different microcystins congeners are known to date and most likely more will be discovered in the near future. However, the risk assessment calculations are based on the toxicokinetic and -dynamic property of one single MC congener, namely MC-LR

- Multiple MC congeners can occur simultaneously in a cyanobacterial bloom, emphasizing the uncertainty in estimating true toxic potency in a bloom situation

- MC-congeners display distinct differences in organ distribution and location of toxic effects (Gupta et al. 2003; Milutinovic et al. 2002; 
Milutinovic et al. 2003) strongly suggesting that these differences are governed primarily by the affinities of the respective microcystin congeners for the transporting proteins present in the different organs, i.e. also on their expression levels ((Fischer et al. 2005), see above)

- The comparison of different species (rodents versus humans) strongly suggests that microcystin transporting proteins are neither identical nor comparable amongst species; neither in their level of expression and distribution amongst organs of a given species nor in their respective microcystin transporting capabilities. This strongly indicates that risk extrapolation from rodents to the humans, despite the inclusion of a safety factor of 10 for inter-species extrapolation (Dietrich and Hoeger 2005), may underestimate the potential risk posed by the different toxins to humans.

- Additive, synergistic or antagonistic effects of the various microcystin congeners have so far not been investigated.

- Current risk assessment schemes, although incorporating allocation factors for contribution to total toxin exposure from sources other than the main source (drinking water), fail to consider route and matrix differences in bioavailability that may exist.

In order to understand the toxicities, bioavailabilities and toxicokinetics and -dynamics of single toxins and extracts, additional studies are needed and are essential for an improved risk assessment.

Obviously, the above uncertainties in the risk assessment of microcystins also emphasize the problems of establishing highly reliable guidance values for drinking water, inhalation exposure, or voluntary exposure via consumption of BGAS. Moreover, similar risk calculations for other toxic compounds e.g. cylindrospermopsin (CYN), anatoxins (ANA) saxitoxins (STX) and $\beta$-methylamino-L-alanine (BMAA), as well as the ubiquitously present lipopolysaccharides (LPS) are still under development but also fraught with the problems described for microcystins. Indeed, with the exception of BMAA (see below), a good understanding of the uptake and distribution kinetics of the other cyanobacterial toxins is nearly completely lacking to date. Thus, all calculations in the risk assessment process would have to be based on physico-chemical characteristics of the toxins.

Anatoxin-a, homoanatoxin-a, anatoxin-a(S), saxitoxins and cylindrospermopsin are very small molecules, with molecular weights of 165, 179, 252, 299 and 415, respectively, and thus are assumed to be able to cross the cell membranes via diffusion or facilitated diffusion. However, to date 
there is no proof for these assumptions, emphasizing again the dearth of information available for risk assessment purposes.

BMAA ( $\beta-\mathrm{N}-$ methylamino-L-alanine), a cyanobacterial, neurotoxic, nonprotein amino acid, acts as an agonist of animal glutamate receptors (Brenner et al. 2003) and is chemically related to excitant amino acids. Its uptake into brain is most likely mediated by the large neutral amino acid carrier of the blood-brain barrier (Smith and Shine 1992). BMAA has been associated with the significantly increased incidences of amyotrophic lateral sclerosis/parkinsonism-dementia complex (ALS/PDC) among the Chamorro people in Guam and other islands of the Pacific. BMAA, originating from cyanobacterial cycad root symbionts of the genus Nostoc, was demonstrated to bioaccumulate at various trophic levels including-in some of the traditional foods of these inhabitants of these islands (Cox et al. 2003). However, recently Cox et al. (2005) revealed that BMAA production by cyanobacteria appeared most likely to be a general phenomenon, as BMAA was detected in 95\% of 21 cyanobacterial genera. Indeed, most recent GC-MS/MS analyses of Aph. flos-aquae and Spirulina spec. containing BGAS demonstrated large quantities of BMAA (Dietrich unpublished data). If BMAA is indeed involved in the aetiology of ALS/PDC, the findings of BMAA in BGAS may potentially explain the detection of BMAA in brain tissues of Canadians with Alzheimer's disease (Cox 2005). Although it would have to be established whether or not these patients had consumed BGAS at any given time. The presence of BMAA, although not highly toxic in an acute scenario, profusely demonstrates that indeed, cyanobacterial bloom toxicity is NOT a single toxin scenario but most likely a combinatorial toxicity of many toxins present. Consequently, risk assessments must take these issues into consideration, even though to do so may prove extremely difficult.

\section{Extract toxicity and synergisms}

As a consequence of the limited knowledge on cyanotoxins other than MCs and BMAA, e.g. CYN, ANA, etc., the additional factors influencing potential risk i.e. antagonistic, additive or synergistic toxicity of simultaneously occurring cyanobacterial toxins has largely been ignored. Although antagonistic effects have so far not been reported they have also not been subject of specific toxicological studies. Additive or synergistic toxicity has been suggested by a number of observations. Indeed, cyanobacterial extracts have shown much greater toxicity then what would have been expected from the amounts of toxins (e.g. MCs) contained in the respective samples. 
The following examples may serve as an illustration the potential presence of additive or synergistic toxicity of extracts: Majsterek et al. (2004) reported on the increased toxicity of a MC-LR containing extract compared to a microcystin-LR standard employing a cytochrome c oxidase assay using mammalian mitochondria from Bos taurus. The extract inhibited the activity of mitochondrial oxidase to a much higher extent than the same concentration of purified MC-LR standard. These authors assumed that the extract contained additional congeners of MC not detected with their means of chemical analysis.

Another potential explanation for the increased extract toxicity was provided by Best et al. (2002), who investigated the effect of lipopolysaccharides (LPS) from axenic cyanobacteria and from natural blooms on the activity of microsomal (m) and soluble (s) glutathione $S$-transferase (GST) of zebra fish embryos (Danio rerio) in vivo. Both activities were significantly reduced by cyanobacterial LPS, as well as by co-exposure to cyanobacterial LPS and MC-LR. Hence, they concluded that LPS may potentially cause inhibition of the GST catalyzed conjugation of MCs to glutathione, which represents the first step in detoxification of MCs and therefore may prolong residence time of MCs in the zebrafish resulting in a much higher toxicity and what was expected from pure MC-LR.

Fitzgeorge et al. (1994) compared the toxicities of anatoxin-a and MCLR with the toxicity of both toxins administered simultaneously. An intranasal $\mathrm{LD}_{50}$ of $2000 \mu \mathrm{g} \mathrm{kg}^{-1}$ bw for anatoxin-a and a non-lethal dose of $31.3 \mu \mathrm{g} \mathrm{kg}^{-1}$ bw for MC-LR were determined in mice. Upon administration of $31.3 \mu \mathrm{g} \mathrm{kg}^{-1}$ bw MC-LR 30 minutes prior to anatoxin-a, the $\mathrm{LD}_{50}$ for anatoxin-a was lowered to $500 \mu \mathrm{g} \mathrm{kg}^{-1} \mathrm{bw}$. This potential synergistic effect of anatoxin-a and MC-LR was further investigated by Rogers et al. (2005) using oral toxin administration. Mice were gavaged with either 0 , 500 or $1000 \mu \mathrm{g}$ microcystin-LR kg-1 bw, followed by $0,500,1000$ or 2500 $\mu \mathrm{g}$ anatoxin-a kg ${ }^{-1}$ bw 50 minutes later. Despite the high concentrations used, no deaths, no clinical signs of intoxication and no differences in weight between pre- and post-treatment were reported. It was concluded that the failure in demonstrating the synergistic effect was most likely due to the different routes toxin administration. Indeed, intranasal application of toxins resulted in similar $\mathrm{LD}_{50} \mathrm{~S}$ as did i.p. application, while the oral $\mathrm{LD}_{50}$ of MC-LR in mice was approximately $12-$ fold higher than the i.p. or intranasal administration (Fitzgeorge et al. 1994). These findings, although yet uncorroborated in a more wide assessment of toxin interactions, suggest that the route of exposure as well as the toxin composition may be critical for the onset of adverse effects. In view of the vast differences of toxin transporter presence and level of expression in the different organs, 
as is the case for MCs and BMAA, it is not surprising to see route of administration dependent differences in $\mathrm{LD}_{50} \mathrm{~S}$ as well as differences in the potential for additive or synergistic effects. Consequently, extrapolation from various routes of exposure as a means for an overall risk assessment may be quite problematic.

\section{Conclusions}

The present analysis of the data on cyanobacterial toxins and their use within the context of risk assessment demonstrates that the dearth of information precludes development of simple safety assumptions. Although the WHO drinking water guidance value for MCs may provide a little more certainty due to the physiologically limited quantity of drinking water per person per day, the simultaneous presence of other toxins in the drinking water questions the reliability of this guidance value as it is expressively specified for only one (MC-LR) of the $>80$ presently known toxin congeners and does not take other congeners or other toxins types into consideration. The provisional guidance value for BGAS as proposed by the Oregon Department of Health of $1 \mu \mathrm{g}$ MC-LR equiv. $\mathrm{g}^{-1} \mathrm{dw}$ BGAS, when considering the potential for additive or synergistic effects stemming from the presence of other cyanobacterial toxins in bloom situations in Klamath Lake, as well as the nearly unlimited voluntary daily uptake of these compounds by the public and especially children, is even more problematic. The latter situation appears even more of a concern because recent analyses confirmed the presence of BMAA and microcystins in these BGAS products, thus clearly emphasizing the high potential for the onset of hepatic, renal and neurological disorders in these children, whether or not this may be of the subacute/subchronic (MCs), or the delayed (MCs and BMAA) type. While sale of BGAS should be severely controlled or even restricted, authorities and academia should be supported in developing additional data pertaining to the inhalation and the food contamination exposure scenarios. 
Table 1. Calculated possible daily ingestion to avoid acute health problems according to the calculations of Fromme et al. (2000). For details, see Dietrich et al (2005)

\begin{tabular}{|c|c|c|c|c|}
\hline Ingestion route & $\begin{array}{c}\text { MC concen- } \\
\text { trations }\end{array}$ & $\begin{array}{c}\text { Infants } \\
5 \mathrm{~kg}=12.5 \mu \mathrm{g}\end{array}$ & $\begin{array}{c}\text { Children } \\
20 \mathrm{~kg}=50 \mu \mathrm{g}\end{array}$ & $\begin{array}{c}\text { Adults } \\
60 \mathrm{~kg}=150 \mu \mathrm{gg}\end{array}$ \\
\hline Food & $\begin{array}{l}100 \mu \mathrm{g} \mathrm{kg}^{-1} \\
10000 \mu \mathrm{gg}^{-1}\end{array}$ & $\begin{array}{l}125 \mathrm{~g} \\
1.25 \mathrm{~g}\end{array}$ & $\begin{array}{l}500 \mathrm{~g} \\
5 \mathrm{~g}\end{array}$ & $\begin{array}{l}1,500 \mathrm{~g} \\
15 \mathrm{~g}\end{array}$ \\
\hline $\begin{array}{l}\text { Cyanobacterial } \\
\text { bloom in lake/river }\end{array}$ & $\begin{array}{l}100 \mu g \mathrm{l}^{-1} \\
1000 \mu \mathrm{g} \mathrm{l}^{-1}\end{array}$ & $\begin{array}{l}125 \mathrm{ml} \\
12.5 \mathrm{ml}\end{array}$ & $\begin{array}{l}500 \mathrm{ml} \\
50 \mathrm{ml}\end{array}$ & $\begin{array}{l}1,500 \mathrm{ml} \\
150 \mathrm{ml}\end{array}$ \\
\hline Drinking water & $\begin{array}{l}1.0 \mu g \mathrm{l}^{-1} \\
100 \mu g \mathrm{l}^{-1}\end{array}$ & $\begin{array}{l}12,500 \mathrm{ml} \\
125 \mathrm{ml}\end{array}$ & $\begin{array}{l}50,000 \mathrm{ml} \\
500 \mathrm{ml}\end{array}$ & $\begin{array}{l}150,000 \mathrm{ml} \\
1,500 \mathrm{ml}\end{array}$ \\
\hline BGAS & $\begin{array}{l}1.0 \mu g^{-1} \\
10 \mu g^{-1}\end{array}$ & $\begin{array}{l}12.5 \mathrm{~g} \\
1.25 \mathrm{~g}\end{array}$ & $\begin{array}{l}50 \mathrm{~g} \\
5 \mathrm{~g}\end{array}$ & $\begin{array}{l}150 \mathrm{~g} \\
15 \mathrm{~g}\end{array}$ \\
\hline
\end{tabular}


Table 2. Known and possible transporters of microcystins and their known distribution in human and rodent organ system. oatp: organic anion transporting polypeptide; mdr: multidrug resistance proteins; mrp: multidrug resistance associated Proteins, human transporters are generally written in upper case, rodent transporters in lower case.

\begin{tabular}{|c|c|c|c|c|}
\hline Organs & Transporter & Human & $\begin{array}{l}\text { Rat/ } \\
\text { Mouse }\end{array}$ & References \\
\hline \multirow[t]{3}{*}{$\begin{array}{l}\text { Gastro- } \\
\text { Intestinal } \\
\text { Tract }\end{array}$} & OATPs/Oatps & $\begin{array}{l}\text { 2A1, (2B1), } \\
3 \mathrm{~A} 1,4 \mathrm{~A} 1\end{array}$ & 1a5 & $\begin{array}{l}\text { (Cheng et al. } \\
\text { 2005; Hagen- } \\
\text { buch and Daw- } \\
\text { son 2004; Ho } \\
\text { and Kim 2005) }\end{array}$ \\
\hline & MDR/Mdr & 1 & $1 \mathrm{a}, 1 \mathrm{~b}$ & $\begin{array}{l}\text { (Faber et al. } \\
\text { 2003; Ho and } \\
\text { Kim 2005) }\end{array}$ \\
\hline & MRP/Mrp & $1-3,5,7-9$ & $1-3$ & $\begin{array}{l}\text { (Faber et al. } \\
\text { 2003; Glavinas } \\
\text { et al. 2004; Ho } \\
\text { and Kim 2005) }\end{array}$ \\
\hline \multirow[t]{3}{*}{ Liver } & OATPs/Oatps & $\begin{array}{l}\text { 1A2*, 1B1*, } \\
\text { 1B3*, 2A1, } \\
\text { (2B1), 3A1, } \\
4 \mathrm{~A} 1\end{array}$ & $\begin{array}{l}(1 \mathrm{a} 1) \\
(1 \mathrm{a} 4), \\
1 \mathrm{~b} 2^{*} \\
2 \mathrm{~b} 1\end{array}$ & $\begin{array}{l}\text { (Cheng et al. } \\
\text { 2005; Hagen- } \\
\text { buch and Daw- } \\
\text { son 2004) }\end{array}$ \\
\hline & $\mathrm{MDR} / \mathrm{Mdr}$ & $1,2 / 3$ & $\begin{array}{l}1 \mathrm{~b}, 1 \mathrm{a}, \\
2\end{array}$ & $\begin{array}{l}\text { (Faber et al. } \\
\text { 2003; Glavinas } \\
\text { et al. 2004; Ho } \\
\text { and Kim 2005; } \\
\text { van Montfoort et } \\
\text { al. 2003) }\end{array}$ \\
\hline & MRP/Mrp & $1-3,5-9$ & $1-3,6$ & $\begin{array}{l}\text { (Faber et al. } \\
\text { 2003; Glavinas } \\
\text { et al. 2004; Ho } \\
\text { and Kim 2005; } \\
\text { van Montfoort et } \\
\text { al. 2003) }\end{array}$ \\
\hline
\end{tabular}




\begin{tabular}{|c|c|c|c|c|}
\hline Organs & Transporter & Human & $\begin{array}{l}\text { Rat/ } \\
\text { Mouse }\end{array}$ & References \\
\hline \multirow[t]{3}{*}{ Kidney } & OATPs/Oatps & $\begin{array}{l}1 \mathrm{~A} 2 *, 2 \mathrm{~A} 1, \\
3 \mathrm{~A} 1,4 \mathrm{~A} 1, \\
4 \mathrm{C} 1\end{array}$ & $\begin{array}{l}\text { (1a1), } \\
1 \mathrm{a} 3, \\
1 \mathrm{a} 6, \\
3 \mathrm{a} 1, \\
4 \mathrm{c} 1\end{array}$ & $\begin{array}{l}\text { (Cheng et al. } \\
\text { 2005; Hagen- } \\
\text { buch and Daw- } \\
\text { son 2004) }\end{array}$ \\
\hline & MDR/Mdr & 1 & $1 \mathrm{a}, 1 \mathrm{~b}$ & $\begin{array}{l}\text { (Glavinas et al. } \\
\text { 2004; Ho and } \\
\text { Kim 2005; van } \\
\text { Montfoort et al. } \\
\text { 2003) }\end{array}$ \\
\hline & MRP/Mrp & $1-9$ & 2 & $\begin{array}{l}\text { (Glavinas et al. } \\
\text { 2004; Ho and } \\
\text { Kim 2005; } \\
\text { Robertson and } \\
\text { Rankin 2006; } \\
\text { van Montfoort et } \\
\text { al. 2003) }\end{array}$ \\
\hline \multirow[t]{3}{*}{ Blood-Brain } & OATPs/Oatps & $\begin{array}{l}1 \mathrm{~A} 2 *, 1 \mathrm{C} 1, \\
2 \mathrm{~A} 1,3 \mathrm{~A} 1, \\
4 \mathrm{~A} 1\end{array}$ & $\begin{array}{l}\text { (1a4), } \\
1 \mathrm{c} 1\end{array}$ & $\begin{array}{l}\text { (Cheng et al. } \\
\text { 2005; Hagen- } \\
\text { buch and Daw- } \\
\text { son 2004) }\end{array}$ \\
\hline & MDR/Mdr & 1 & $1 \mathrm{a}$ & $\begin{array}{l}\text { (Glavinas et al. } \\
\text { 2004; Hagen- } \\
\text { buch et al. 2002; } \\
\text { Ho and Kim } \\
\text { 2005) }\end{array}$ \\
\hline & MRP/Mrp & $1,5,7-9$ & 2 & $\begin{array}{l}\text { (Glavinas et al. } \\
\text { 2004; Hagen- } \\
\text { buch and Daw- } \\
\text { son 2004; } \\
\text { Hagenbuch et al. } \\
\text { 2002; Ho and } \\
\text { Kim 2005) }\end{array}$ \\
\hline
\end{tabular}

* dihydro - MC-LR transport demonstrated by Fischer et al (Fischer et al. 2005)

() no dihydro - MC-LR transport 


\section{References}

Adelman WJ Jr, Fohlmeister JF, Sasner JJ Jr, Ikawa M (1982) Sodium channels blocked by aphantoxin obtained from the blue-green alga, Aphanizomenon flos-aquae. Toxicon 20 513-516

Azevedo SM, Carmichael WW, Jochimsen EM, Rinehart KL, Lau S, Shaw GR, Eaglesham GK (2002) Human intoxication by microcystins during renal dialysis treatment in Caruaru-Brazil. Toxicology 181-182 441-446

Ballatori N, Hammond CL, Cunningham JB, Krance SM, Marchan R (2005) Molecular mechanisms of reduced glutathione transport: role of the MRP/CFTR/ABCC and OATP/SLC21A families of membrane proteins. Toxicology and Applied Pharmacology 204 238- 255

Ballot A, Krienitz L, Kotut K, Wiegand C, Metcalf JS, Codd GA, Pflugmacher S (2004) Cyanobacteria and cyanobacterial toxins in three alkaline rift valley lakes of Kenya - Lakes Bogoria, Nakuru and Elmenteita. Journal of Plankton Research 26 925-935

Ballot A, Krienitz L, Kotut K, Wiegand C, Pflugmacher S (2005) Cyanobacteria and cyanobacterial toxins in the alkaline crater lakes Sonachi and Simbi, Kenya. Harmful Algae 4 139-150

Banker R, Carmeli S, Hadas O, Teltsch B, Porat R, Sukenik A (1997) Identification of cylindrospermopsin in Aphanizomenon ovalisporum (Cyanophyceae) isolated from Lake Kinneret, Israel. Journal of Phycology 33 613-616

Barica J (1978) Collapses of Aphanizomenon flos-aquae blooms resulting in massive fish kills in eutrophic lakes: effect of weather. Verhandlungen der Internationalen Vereinigung für Limonologie 20 208-213

Best J, Pflugmacher S, Wiegand C, Eddy F, Metcalf J, Codd G (2002) Effects of enteric bacterial and cyanobacterial lipopolysaccharides, and of microcystinLR, on glutathione S-transferase activities in zebra fish (Danio rerio). Aquatic Toxicology 60(3-4) 223-231

Bhattacharya R, Sugendran K, Dangi RS, Rao PV (1997) Toxicity evaluation of freshwater cyanobacterium Microcystis aeruginosa PCC 7806: II. Nephrotoxicity in rats. Biomedical and Environmental Sciences 10 93-101

Brenner ED, Stevenson DW, McCombie RW, Katari MS, Rudd SA, Mayer KF, Palenchar PM, Runko SJ, Twigg RW, Dai G, Martienssen RA, Benfey PN, Coruzzi GM (2003) Expressed sequence tag analysis in Cycas, the most primitive living seed plant. Genome Biology 4(12) R78

Burns JW (2004) Cyanotoxins in Floridas (USA) surface waters: considerations for water supply planning. In ICTC $6^{\text {th }}$, Bergen/Norway, pp 4

Carmichael WW, Drapeau C, Anderson DM (2000) Harvesting of Aphanizomenon flos-aquae Ralfs ex Born \& Flah var flos-aquae (Cyanobacteria) from Klamath Lake for human dietary use. Journal of Applied Phycology 12 585595

Cheng X, Maher J, Chen C, Klaassen CD (2005) Tissue distribution and ontogeny of mouse organic anion transporting polypeptides (Oatps). Drug Metabolism and Disposition 33 1062-1073 
Chorus I, Bartram J (1999) Toxic cyanobacteria in water. A guide to their public health consequences, monitoring and management. World Health Organization, E \& FN Spon London, pp 416

Cox P, Banack S, Murch S (2003) Biomagnification of cyanobacterial neurotoxins and neurodegenerative disease among the Chamorro people of Guam. Proceedings of the National Academy of Sciences of the United States of America 100 13380-13383

Cox PA, Banack SA, Murch SJ, Rasmussen U, Tien G, Bidigare RR, Metcalf JS, Morrison LF, Codd GA, Bergman B (2005) Diverse taxa of cyanobacteria produce beta-N-methylamino-L-alanine, a neurotoxic amino acid. Proceedings of the National Academy of Sciences of the United States of America 102 5074-5078

Dietrich DR, Hoeger SJ (2005) Guidance values for microcystins in water and cyanobacterial supplement products (blue-green algal supplements): a reasonable or misguided approach? Toxicology and Applied Pharmacology 203 273-289

Draisci R, Ferretti E, Palleschi L, Marchiafava C (2001) Identification of anatoxins in blue-green algae food supplements using liquid chromatographytandem mass spectrometry. Food Additives and Contaminants 18 525-531

Ekman-Ekebom M, Kauppi M, Sivonen K, Niemi M, Lepisto L (1992) Toxic Cyanobacteria in some Finnish Lakes. Environmental Toxicology \& Water Quality 7 201-213

Ernst B, Dietz L, Hoeger SJ, Dietrich DR (2005) Recovery of MC-LR in fish liver tissue. Environmental Toxicology 20 449-458

Faber KN, Müller M, Jansen PLM (2003) Drug transport proteins in the liver. Advanced Drug Delivery Reviews 55 107-124

Ferreira FMB, Soler JMF, Fidalgo ML, Fernandez-Vila P (2001) PSP toxins from Aphanizomenon flos-aquae (cyanobacteria) collected in the Crestuma-Lever reservoir (Douro river, northern Portugal). Toxicon 39 757-761

Fischer WJ, Altheimer S, Cattori V, Meier PJ, Dietrich DR, Hagenbuch B (2005) Organic anion transporting polypeptides expressed in liver and brain mediate uptake of microcystin. Toxicology and Applied Pharmacology 203 257-263

Fischer WJ, Dietrich DR (2000) Pathological and biochemical characterization of microcystin-induced hepatopancreas and kidney damage in carp (Cyprinus carpio). Toxicology and Applied Pharmacology 164 73-81

Fitzgeorge RB, Clark SA, Keevil CW (1994) Routes of intoxication. In Detection methods for cyanobacterial toxins, Codd GA, Jefferies TM, Keevil CW, Potter E (eds) vol 149 Royal Society of Chemistry, Cambridge, UK

Fromme H, Koehler A, Krause R, Fuehrling D (2000) Occurrence of cyanobacterial toxins- microcystins and anatoxin-a-in Berlin water bodies with implications to human health and regulations. Environmental Toxicology 15 120-130

Gentile JH, Maloney TE (1969) Toxicity and environmental requirements of a strain of Aphanizomenon flos-aquae (L.) Ralfs. Canadian Journal of Microbiology 15 165-173 
Gilroy DJ, Kauffman KW, Hall RA, Huang X, Chu FS (2000) Assessing potential health risks from microcystin toxins in blue-green algae dietary supplements. Environmental Health Perspectives 108 435-439

Glavinas H, Krajcsi P, Cserepes J, Sarkadi B (2004) The Role of ABC Transporters in Drug Resistance, Metabolism and Toxicity. Current Drug Delivery 1 27-42

Gupta N, Pant SC, Vijayaraghavan R, Rao PV (2003) Comparative toxicity evaluation of cyanobacterial cyclic peptide toxin microcystin variants (LR, RR, YR) in mice. Toxicology 188 285-296

Hagenbuch B, Dawson P (2004) The sodium bile salt co-transport family SLC10. Pflugers Archiv 447 566-570

Hagenbuch B, Gao B, Meier PJ (2002) Transport of xenobiotics across the bloodbrain barrier. News in Physiological Sciences 17 231-234

Hagenbuch B, Meier PJ (2003) The superfamily of organic anion transporting polypeptides. Biochimica et Biophysica Acta 1609 1-18

Hagenbuch B, Meier PJ (2004) Organic anion transporting polypeptides of the OATP/ SLC21 family: phylogenetic classification as OATP/ SLCO superfamily, new nomenclature and molecular/functional properties. Pflugers Archiv 447 653-665

Hitzfeld B, Lampert C, Späth N, Mountfort D, Kaspar H, Dietrich D (2000a) Toxin production in cyanobacterial mats from ponds on the McMurdo Ice Shelf, Antarctica. Toxicon 38 1731-1748

Hitzfeld BC, Hoeger SJ, Dietrich DR (2000b) Cyanobacterial toxins: removal during drinking water treatment, and human risk assessment. Environmental Health Perspectives 108 Supplement 1 113-122

Ho RH, Kim RB (2005) Transporters and drug therapy: Implications for drug disposition and disease. Clinical Pharmacology and Therapeutics 78 260-277

Hoeger SJ, Dietrich DR (2004) Possible health risks arising from consumption of blue-green algae food supplements. In ICTC $6^{\text {th }}$, Bergen/Norway, pp 30

Hoeger SJ, Hitzfeld, BC, Dietrich DR (2005) Occurrence and elimination of cyanobacterial toxins in drinking water treatment plants. Toxicology and Applied Pharmacology 203 231-242

Hoeger SJ, Shaw G, Hitzfeld BC, Dietrich DR (2004) Occurrence and elimination of cyanobacterial toxins in two Australian drinking water treatment plants. Toxicon 43 639-649

Hoppu K, Salmela J, Lahti K (2002) High risk for symptoms from use of water contaminated with cyanobacteriae in sauna. Clinical Toxicology 40 309-310

Iwasa M, Yamamoto M, Tanaka Y, Kaito M, Adachi Y (2002) Spirulinaassociated hepatotoxicity. American Journal of Gastroenterology 973212 3213

Jacquemin D, Hagenbuch B, Stieger B, Wolfkoff AW, Meier PJ (1994) Expression cloning of a rat liver $\mathrm{Na}+-$-independent organic anion transporter. Proceedings of the National Academy of Sciences of the USA 91 133-137

Jacquemin E, Hagenbuch B, Stieger B, Wolkoff AW, Meier PJ (1991) Expression of the hepatocellular chloride-dependent sulfobromophthalein uptake system in Xenopus laevis oocytes. Journal of Clinical Investigations 88 2146-2146 
Jochimsen EM, Carmichael WW, An JS, Cardo DM, Cookson ST, Holmes CE, Antunes MB, de Melo Filho DA, Lyra TM, Barreto VS, Azevedo SM, Jarvis WR (1998) Liver failure and death after exposure to microcystins at a hemodialysis center in Brazil [published erratum appears in N Engl J Med $1998 \mathrm{Jul}$ 9;339(2):139]. New England Journal of Medicine 338 873-878

Khan SA, Wickstrom M, Haschek W, Schaeffer S, Ghosh S, Beasley V (1996) Microcystin-LR and kinetics of cytoskeletal reorganization in hepatocytes, kidney cells, and fibroblasts. Natural Toxins 4 206-214

Kuiper-Goodman T, Falconer IR, Fitzgerald DJ (1999) Human Health Aspects. In Toxic Cyanobacteria in Water: A Guide to their Public Health Consequences, Monitoring and Management, Chorus I, Bartram J (eds) E \& FN Spon, London, pp 114-153

Kunta JR, Sinko PJ (2004) Intestinal Drug Transporters: In Vivo Function and Clinical Importance. Current Drug Metabolism 5 109-124

Landsberg JH (2002) The Effect of Harmful Algal Blooms on Aquatic Organisms. Reviews in Fisheries Sciences 10 113-390

Lawrence JF, Niedzwiadek B, Menard C, Lau BP, Lewis D, Kuiper-Goodman T, Carbone S, Holmes C (2001) Comparison of liquid chromatography/mass spectrometry, ELISA, and phosphatase assay for the determination of microcystins in blue-green algae products. Journal of the AOAC International 84 1035-1044

Maatouk I, Bouaicha N, Fontan D, Levi Y (2002) Seasonal variation of microcystin concentrations in the Saint-Caprais reservoir (France) and their removal in a small full-scale treatment plant. Water Research 36 2891-2897

Mahmood NA, Carmichael WW (1986) Paralytic shellfish poisons produced by the freshwater cyanobacterium Aphanizomenon flos-aquae $\mathrm{NH}-5$. Toxicon 24 175-186

Majsterek I, Sicinska P, Tarczynska M, Zalewski M, Walter Z (2004) Toxicity of microcystin from cyanobacteria growing in a source of drinking water. Comparative Biochemistry and Physiology C 139 175-179

Meier PJ, Stieger B (2002) Bile salt transporters. Annual Review of Physiology 64 635-661

Meriluoto JA, Nygard SE, Dahlem AM, Eriksson JE (1990) Synthesis, organotropism and hepatocellular uptake of two tritium-labeled epimers of dihydromicrocystin-LR, a cyanobacterial peptide toxin analog. Toxicon 28 1439-1446

Milutinovic A, Sedmak B, Horvat-Znidarsic I, Suput D (2002) Renal injuries induced by chronic intoxication with microcystins. Cellular and Molecular Biology Letters 7 139-141

Milutinovic A, Zivin M, Zorc-Pleskovic R, Sedmak B, Suput D (2003) Nephrotoxic effects of chronic administration of microcystins - LR and $-Y$ R. Toxicon 42 281-288

Miyazaki H, Sekine T, Endou H (2004) The multispecific organic anion transporter family: properties and pharmacological significance. Trends in Pharmacological Sciences 25(12) 654-662 
Moreno I, Pichardo S, Jos A, Gomez-Amores L, Mate A, Vazquez CM, Camean AM (2005) Antioxidant enzyme activity and lipid peroxidation in liver and kidney of rats exposed to microcystin-LR administered intraperitoneally. Toxicon 45 395-402

Nies AT, Jedlitschky G, König J, Herold-Mende C, Steiner HH, Schmitt H-P, Keppler D (2004) Expression and Immunolocalization of the Multidrug Resistance Proteins, MRP1-MRP6 (ABCC1-ABCC6), in human brain. Neuroscience 129 349-360

Osborne NJ, Webb PM, Shaw GR (2001) The toxins of Lyngbya majuscula and their human and ecological health effects. Environment International 27 381392

Pace JG, Robinson NA, Miura GA, Lynch TG, Templeton CB (1990) Pharmacokinetics, metabolism and distribution of microcystin ([3H]Mcyst-LR) in the rat. The Toxicologist 10219

Pereira P, Onodera H, Andrinolo D, Franca S, Araujo F, Lagos N, Oshima Y (2000) Paralytic shellfish toxins in the freshwater cyanobacterium Aphanizomenon flos-aquae, isolated from Montargil reservoir, Portugal. Toxicon 38 1689-1702

Pflugmacher S, Wiegand C, Oberemm A, Beattie KA, Krause E, Codd GA, Steinberg CE (1998) Identification of an enzymatically formed glutathione conjugate of the cyanobacterial hepatotoxin microcystin-LR: the first step of detoxication. Biochimica Biophysica Acta 1425 527-533

Picanco MR, Soares RM, Cagido VR, Azevedo SM, Rocco PR, Zin WA (2004) Toxicity of a cyanobacterial extract containing microcystins to mouse lungs. Brazilian Journal of Medical and Biological Research 37 1225-1229

Pilotto L, Douglas R, Burch M, Cameron S, Beers M, Rouch G, Robinson P, Kirk M, Cowie C, Hardiman S, Moore C, Attewell R (1997) Health effects of exposure to cyanobacteria (blue-green algae) during recreational water-related activities. Australian and New Zealand Journal of Public Health 21 562-566

Pouria S, de Andrade A, Barbosa J, Cavalcanti R, Barreto V, Ward C, Preiser W, Poon G, Neild G, Codd G (1998) Fatal microcystin intoxication in haemodialysis unit in Caruaru, Brazil. The Lancet 352 21-26

Rapala J, Sivonen K, Luukkainen R, Niemela SI (1993) Anatoxin-a concentration in Anabaena and Aphanizomenon under different environmental conditions and comparison of growth by toxic and non-toxic Anabaena-strains: A laboratory study. Journal of Applied Phycology 5 581-591

Robertson EE, Rankin GO (2006) Human renal organic anion transporters: Characteristics and contributions to drug and drug metabolite excretion. Pharmacology and Therapy 109(3) 399-412

Robinson NA, Miura GA, Matson CF, Dinterman RE, Pace JG (1989) Characterization of chemically tritiated microcystin-LR and its distribution in mice. Toxicon 27 1035-1042

Robinson NA, Pace JG, Matson CF, Miura GA, Lawrence WB (1991) Tissue distribution, excretion and hepatic biotransformation of microcystin-LR in mice. Journal of Pharmacology and Experimental Therapeutics 256 176-182 
Rogers EH, Hunter ES 3rd, Moser VC, Phillips PM, Herkovits J, Munoz L, Hall LL, Chernoff N (2005) Potential developmental toxicity of anatoxin-a, a cyanobacterial toxin. Journal of Applied Toxicology 25(6) 527-534

Runnegar M, Berndt N, Kaplowitz N (1995) Microcystin uptake and inhibition of protein phosphatases: effects of chemoprotectants and self-inhibition in relation to known hepatic transporters. Toxicology and Applied Pharmacology 134 264-272

Saker M L, Jungblut A-D, Neilan BA, Rawn DFK., Vasconcelos VM (2005) Detection of microcystin synthetase genes in health food supplements containing the freshwater cyanobacterium Aphanizomenon flos-aquae. Toxicon 46 555562

Salazar M, Chamorro GA, Salazar S, Steele CE (1996) Effect of Spirulina maxima consumption on reproduction and peri- and postnatal development in rats. Food Chem Toxicol 34 353-359

Salazar M, Martinez E, Madrigal E, Ruiz LE, Chamorro GA (1998) Subchronic toxicity study in mice fed Spirulina maxima. Journal of Ethnopharmacology 62 235-241

Sawyer PJ, Gentile JH, Sasner JJ Jr (1968) Demonstration of a toxin from Aphanizomenon flos-aquae (L.) Ralfs. Canadian Journal of Microbiology 14 1199-1204

Shaw GR, Sukenik A, Livne A, Chiswell RK, Smith MJ, Seawright AA, Norris RL, Eaglesham GK, Moore MR (1999) Blooms of the cylindrospermopsin containing cyanobacterium, Aphanizomenon ovalisporum (Forti), in newly constructed lakes, Queensland, Australia. Environmental Toxicology 14 167177

Shitara Y, Sato H, Sugiyama Y (2005) Evaluation of drug-drug interaction in the hepatobiliary and renal transport of drugs. Annual Reviews in Pharmacology and Toxicology 45 689-723

Sivonen K, Niemelä SI, Niemi RM, Lepistö L, Luoma TH, Räsänen LA (1990) Toxic cyanobacteria (blue-green) algae in Finnish fresh and coastal waters. Hydrobiologia 190 267-275

Smith GM, Shine HD (1992) Immunofluorescent labeling of tight junctions in the rat brain and spinal cord. International Journal of Development and Neurosciences 10 387-392

Soong FS, Maynard E, Kirke K, Luke C (1992) Illness associated with blue-green algae. Medical Journal of Australia 15667

Stewart I, Webb PM, Schluter PJ, Shaw GR (2001) A prospective epidemiological study of recreational exposure to cyanobacteria in fresh and brackish waters in some Queensland and NSW lakes. In Fifth International Conference on Toxic Cyanobacteria, Noosa, Australia

Stotts RR, Twardock AR, Haschek WM, Choi BW, Rinehart KL, Beasley VR (1997) Distribution of tritiated dihydromicrocystin in swine. Toxicon 35937 953 
Teixera M, Costa M, Carvalho V, Pereira M, Hage E (1993) Gastroenteritis epidemic in the area of the Itaparica Dam, Bahia, Brazil. Bulletin of the PanAmerican Health Organization 27 244-253

Teubner K, Feyerabend R, Henning M, Nicklisch A, Woitke P, Kohl JG (1999) Alternative blooming of Aphanizomenon flos-aquae or Planktothrix agardhii induced by the timing of the critical nitrogen: Phosphorus ratio in hypertrophic riverine lakes. Ergebnisse der Limnologie 54 325-344

Torokne A, Palovics A, Bankine M (2001) Allergenic (sensitization, skin and eye irritation) effects of freshwater cyanobacteria-experimental evidence. Environmental Toxicology 16 512-516

Underdal B, Nordstoga K, Skulberg OM (1999) Protracted toxic effects caused by saline extracts of Aphanizomenon flos-aquae (Cyanophyceae/Cyanobacteria). Aquatic Toxicology 46 269-278

van Montfoort JE, Hagenbuch B, Groothuis GM, Koepsell H, Meier PJ, Meijer DK (2003) Drug uptake systems in liver and kidney. Current Drug Metabolism 4 185-211

Vitale S, Miller NR, Mejico LJ, Perry JD, Medura M, Freitag SK, Girkin C (2004) A randomized, placebo-controlled, crossover clinical trial of super blue-green algae in patients with essential blepharospasm or Meige syndrome. American Journal of Ophthalmology 138 18-32

Wynn-Williams DD (2000) Cyanobacteria in the Deserts - Life at the Limit? In The Ecology of Cyanobacteria, Whitton BA, Potts M (eds) Kluwer Academic Publishers, Dordrecht/London/Boston pp 341-366

Yu FY, Liu BH, Chou HN, Chu FS (2002) Development of a sensitive ELISA for the determination of microcystins in algae. Journal of Agricultural and Food Chemistry 50 4176-4182 